\title{
COVID-19-Associated Histoplasmosis in an AIDS Patient
}

\author{
Rossana Patricia Basso - Vanice Rodrigues Poester (D) J Jéssica Louise Benelli • \\ David A. Stevens • Heruza Einsfeld Zogbi • Izadora Clezar da S. Vasconcellos • \\ Alessandro Comarú Pasqualotto • Melissa Orzechowski Xavier
}

Received: 26 September 2020/ Accepted: 23 October 2020/Published online: 6 November 2020

(C) Springer Nature B.V. 2020

\begin{abstract}
Most reports associating fungal infections with COVID-19 have been cases of invasive aspergillosis. Here, we report a case of severe histoplasmosis and COVID-19 infections in an HIV patient in Rio Grande, Southern Brazil. Histoplasmosis must be included as a diagnostic possibility in opportunistic fungal co-infections in COVID-19 patients with AIDS, mainly in endemic areas.
\end{abstract}

Keywords AIDS · COVID-19 $\cdot$ Histoplasma capsulatum $\cdot$ Mycoses $\cdot$ SARS-CoV-2

Handling Editor: Abdullah Mohammed Said Al-Hatmi.

R. P. Basso - V. R. Poester · J. L. Benelli .

H. E. Zogbi · M. O. Xavier ( $\square)$

Pós-Graduação em Ciências da Saúde, Laboratório de Micologia, Faculdade de Medicina, Universidade Federal do Rio Grande (FAMED-FURG), Campus Saúde, Visconde de Paranaguá 102, Centro, Rio Grande, RS 96201-900, Brazil

e-mail: melissaxavierfurg@gmail.com

R. P. Basso - H. E. Zogbi

Hospital Universitário Dr. Miguel Riet Corrêa Jr. (HUFURG), vinculado à Empresa Brasileira de Serviços

Hospitalares (EBSERH), Rio Grande, RS, Brazil

\section{Introduction}

The COVID-19 pandemia has so far affected more than 39 million people all over the world, causing more than one million deaths [1]. Several co-infections are known to affect patients with severe COVID19 , which may be challenging particularly in terms of diagnosis and treatment, potentially affecting patient outcomes [2,3]. The frequency of COVID-19 in AIDS is not higher than the frequency of COVID-19 in the general population, even though the true role of the SARS-CoV-2 virus in HIV patients remains to be fully elucidated $[4,5]$.

Even more challenging is the diagnosis of fungal infections in patients with COVID-19, with most of the infections being associated with Candida and Aspergillus species [2, 3]. Indeed, coronavirus-associated pulmonary aspergillosis (CAPA) is a concern in COVID-19 patients, occurring in 20-35\% of patients

\footnotetext{
D. A. Stevens - M. O. Xavier

California Institute for Medical Research, San Jose, CA, USA

D. A. Stevens - M. O. Xavier

Division of Infectious Diseases and Geographic Medicine, Stanford University Medical School, Stanford, CA, USA

I. C. S. Vasconcellos · A. C. Pasqualotto

Programa de Pós-Graduação em Patologia, Universidade Federal de Ciências da Saúde de Porto Alegre (UFCSPA), Porto Alegre, RS, Brazil
} 
with severe acute respiratory syndrome (SARS), mainly in those requiring admission to the intensive care unit (ICU) and mechanical ventilation [2, 6, 7]. Similarly, candidemia occurs in $2.5-6.9 \%$ of COVID19 patients in the ICU, mainly catheter-related infections and often with unfavorable outcomes [3, 8]. In addition, individual reports of Pneumocystis spp. coinfection in COVID-19 patients are being described [9, 10].

On the other hand, histoplasmosis, an emergent systemic fungal infection in HIV patients in Brazil and other Latin American countries [11, 12], has not yet been described in the context of COVID-19. Here, we report a case of COVID-19 in a patient who was subsequently diagnosed with histoplasmosis.

\section{Case Report}

A 43-year-old homeless woman from Rio Grande (South of Brazil) with a 21-year history of HIV infection and drug abuse (crack cocaine) was poorly adherent to active antiretroviral treatment (ART). She had two hospitalizations (2012 and 2017) due to neurotoxoplasmosis. Her most recent CD4 count was low, at 113 cells $/ \mathrm{mm}^{3}$, and her HIV viral load was 38,503 RNA copies/ml $(4.58 \mathrm{log})$.

On July 9, 2020, she was admitted to the hospital due to disorientation, cough, dyspnea, and low-grade fever. Chest computed tomography (CT) showed multiple centrilobular nodules, with ground-glass attenuation in both lungs, diffuse thickening of bronchial walls, and lymph node enlargement in the mediastinal and cervical chains and the retroperitoneal upper abdomen (measuring up to $2.7 \mathrm{~cm}$ on its smallest axis). Abdominal CT showed hepatosplenomegaly. Sputum microscopy stained by Gomori-Grocott showed abundant small oval blastoconidia suggestive of Histoplasma capsulatum (Fig. 1), but sputum culture was negative for both Mycobacterium tuberculosis and fungi. Histoplasma and Aspergillus precipitins tests were negative, as well as PCR test for SARS-CoV-2 virus (kit Bio-Manguinhos/FIOCRUZ, Lot 66/2020). She was put on empirical therapy for neurotoxoplasmosis and discharged from the hospital with antiretroviral therapy (tenofovir/lamivudine and atazanavir/ritonavir).

On July 17, 2020, the patient returned with worsening dyspnea and oxygen saturation of $83 \%$.
Dexamethasone (6 mg, intravenous), ceftriaxone, azithromycin, and oxygen supplementation by nasal catheter were prescribed. At this time, she was diagnosed with COVID-19 by a positive PCR test (kit Bio-Manguinhos/FIOCRUZ, Lot 66/2020). Blood testing revealed anemia (hemoglobin of $9.6 \mathrm{~g} / \mathrm{dl}$ ), mild leukocytosis $\left(10,190 / \mathrm{mm}^{3}\right)$, thrombocytopenia $\left(130,000 / \mathrm{mm}^{3}\right)$, and elevated C-reactive protein (140 mg/l) and d-dimer $(2 \mu \mathrm{g} / \mathrm{ml})$. Chest CT showed several sparse micro-nodules in the lungs, with a nodule in the posterior segment of the upper lobe of the right lung (measuring $4 \mathrm{~mm}$ ) and intraparenchymal nodule $(7 \mathrm{~mm})$, lymph node enlargement in the mediastinal and cervical region (up to $2.5 \mathrm{~cm}$ ). Abdominal CT showed confluent lymph node enlargements in the retroperitoneal region (biggest measuring $3 \times 1.7 \mathrm{~cm}$ ) and hepatosplenomegaly (Fig. 2). She was discharged from the hospital, but since the urine sample result became positive for $H$. capsulatum antigen (galactomannan) in immunoenzymatic assay (catalog number HGM201; IMMY®, Immuno-Mycologics, Oklahoma, USA; index of $>2$ ) she was asked to return to the hospital again. She refused hospitalization, and itraconazole PO was commenced at $200 \mathrm{mg}$ twice daily.

Patient was last seen on September 14, 2020. Her HIV viral load was 400 copies/ml $(2.6 \mathrm{log})$, and CD4 count was 593 cells $/ \mathrm{mm}^{3}$. Follow-up abdominal CT showed persistence of hepatosplenomegaly and abdominal lymph node enlargement, while chest CT

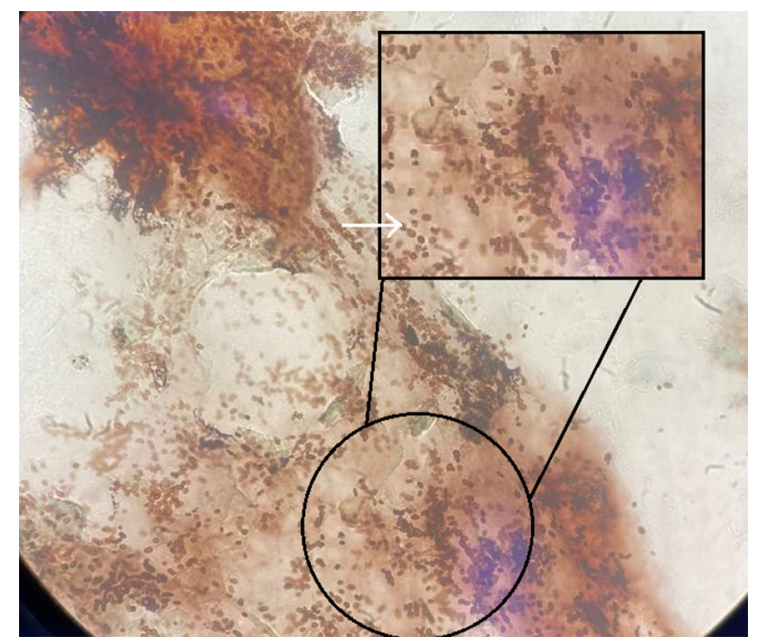

Fig. 1 Sputum microscopy showing abundant small oval blastoconidia (arrow) without pseudo-hyphae (Gomori-Grocott stain) 
Fig. 2 Computed tomography of the chest (a) and abdomen (b) of July 17, 2020. c, d Images show follow-up computed tomography performed on September 14, 2020

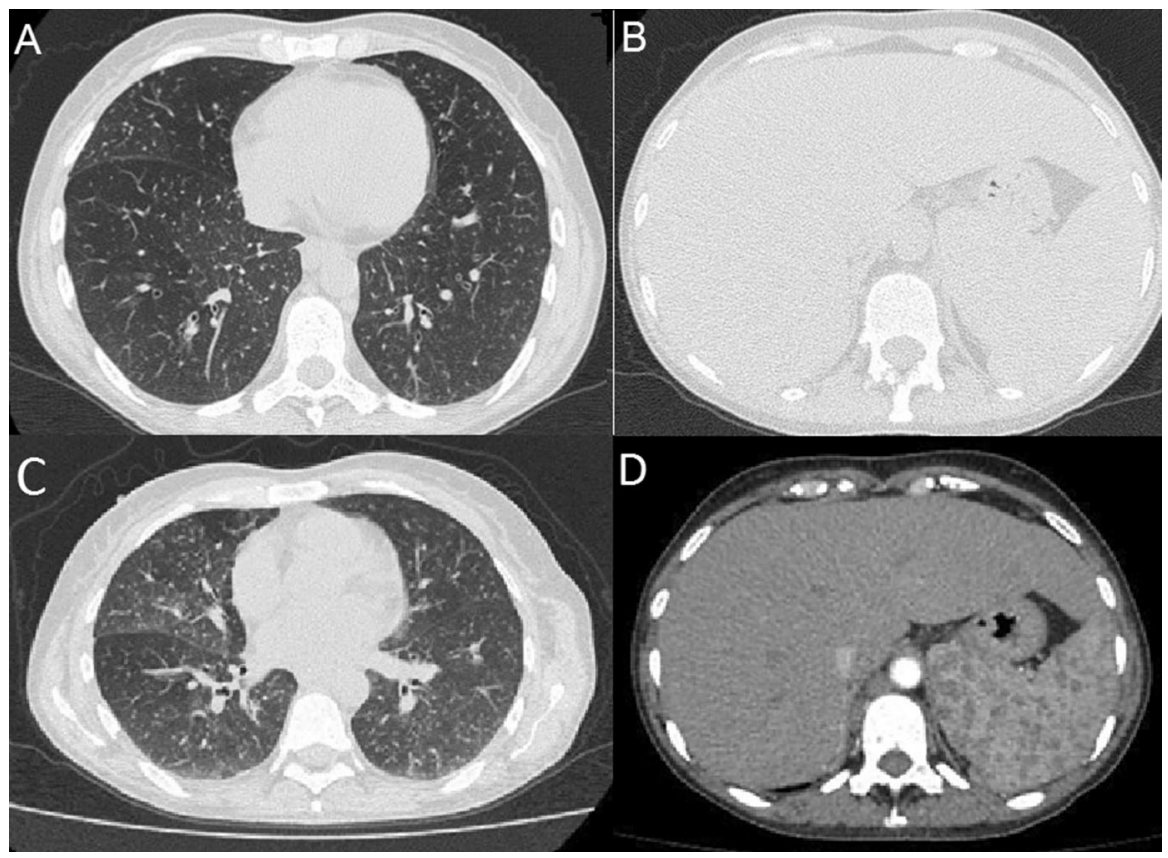

revealed an increase in the number of lymph nodes affected compared to the previous examination from July (Fig. 2). Anemia persisted and an increase in inflammatory markers was detected, suggesting active disease. Her medical team is doing their best in an attempt to readmit the patient to receive IV antifungal therapy.

\section{Discussion}

Here we present the first Brazilian report of disseminated histoplasmosis associated with COVID-19 in an HIV-infected patient. Despite the co-infections with aggressive pathogens, our patient did not develop severe lung deterioration, nor was intensive care and mechanical ventilation necessary. The favorable outcome of COVID-19 in this patient might be related to her low CD4 cell count, which might have prevented the occurrence of a cytokine storm, as described in patients with severe COVID-19, as well as in those initiating antiretroviral therapy with immune reconstitution syndrome [5].

Disseminated histoplasmosis (DH) is one of the most common opportunistic diseases in HIV/AIDS patients and presents many diagnostic challenges. The symptoms are nonspecific and overlap with other opportunistic diseases, and there is a variation in the sensitivity of diagnostic methods (30-95\%) [13, 14]. Our patient was investigated for $\mathrm{DH}$ with the use of the three diagnostic methods available locally, i.e., microscopy, culture, and agar gel immunodiffusion test. Despite being highly suggestive of histoplasmosis, findings at sputum microscopy were not considered definitive and the diagnosis was only made by $H$. capsulatum antigen testing, performed in other institution. Even though antigen testing has a high sensitivity in diagnosing DH (95\%) [14], the method is at the moment available for research purposes only in Brazil. This led to a delay in the diagnosis of DH and consequently in the initiation of treatment, which can affect a patient's outcome. Efforts to increase the availability of the test for urinary antigen detection in DH diagnosis are urgent, especially in regions with a high HIV prevalence [11, 15]. The patient in this report comes from Rio Grande, the municipality with the highest prevalence of HIV/AIDS among Brazilian cities with more than 100,000 inhabitants [16].

Co-infections in COVID-19 and especially in the SARS-CoV-2/HIV patients should be widely investigated since correct treatment would contribute to a favorable outcome [4, 5]. Moreover, fungal infections play an important role as opportunistic infections in HIV or COVID-19 patients, and possible co-infections 
in both populations should be considered, and appropriate screening tests performed [2, 3, 9].

Acknowledgements The authors are grateful to the Coordenação de Aperfeiçoamento de Pessoal de Niv́el Superior from the Ministry of Education, Brazil (CAPES-BR).

\begin{abstract}
Author Contributions All authors contributed to accomplishment of this manuscript. RPB performed care and monitoring of the patient; searched the clinical information; and first draft of the manuscript. VRP contributed to mycological analyses; searched the clinical information; and first draft of the manuscript. JLB and ICSV were involved in mycological analyses. DAS performed critical correction. HEZ was involved in care and monitoring of the patient. ACP and MOX contributed to mycological analyses and critical correction.
\end{abstract}

Funding Not applicable.

Availability of Data and Material Not applicable.

Code Availability Not applicable.

\section{Compliance with Ethical Standards}

Conflict of interest The authors declare that they have no conflict of interest pertaining to this work.

Ethical Approval This project was approved by the Health Research Ethics Committee of the Universidade Federal do Rio Grande (FURG), under number 234/2018 and patient consent was obtained and all procedures performed in studies were in accordance with the ethical standards of the institution.

Informed Consent Informed consent was obtained from all individual participants reported in the study.

\section{References}

1. Coronavirus Worldometer. https://www.worldometers.info/ coronavirus/. Accessed 17 Oct 2020

2. Bartoletti M, Pascale R, Cricca M, Rinaldi M, Maccaro A, Bussini L, et al. Epidemiology of invasive pulmonary aspergillosis among COVID-19 intubated patients: a prospective study. Clin Infect Dis. 2020. https://doi.org/10. 1093/cid/ciaa1065.

3. Antinori S, Bonazzetti C, Gubertini G, Capetti A, Pagani C, Morena V, et al. Tocilizumab for cytokine storm syndrome in COVID-19 pneumonia: an increased risk for candidemia? Autoimmun Rev. 2020;19(7):102564. https://doi.org/10. 1016/j.autrev.2020.102564.

4. Vizcarra P, Pérez-Elías MJ, Quereda C, Moreno A, Vivancos MJ, Dronda F, et al. Description of COVID-19 in HIV-infected individuals: a single-centre, prospective cohort. Lancet HIV. 2020;7(8):e554-64. https://doi.org/10. 1016/S2352-3018(20)30164-8.
5. Xu Z, Zhang C, Wang F-S. COVID-19 in people with HIV. Lancet HIV. 2020;7(8):e524-6. https://doi.org/10.1016/ S2352-3018(20)30163-6.

6. Rutsaert L, Steinfort N, Van Hunsel T, Bomans P, Naesens $\mathrm{R}$, Mertes $\mathrm{H}$, et al. COVID-19-associated invasive pulmonary aspergillosis. Ann Intensive Care. 2020;10(1):71. https://doi.org/10.1186/s13613-020-00686-4.

7. van Arkel ALE, Rijpstra TA, Belderbos HNA, van Wijngaarden P, Verweij PE, Bentvelsen RG. COVID-19-associated Pulmonary Aspergillosis. Am J Respir Crit Care Med. 2020;202(1):132-5. https://doi.org/10.1164/rccm. 202004-1038LE.

8. Chowdhary A, Tarai B, Singh A, Sharma A. Multidrugresistant Candida auris infections in critically Ill coronavirus disease patients, India, April-July 2020. Emerg Infect Dis J. 2020. https://doi.org/10.3201/eid2611.203504.

9. Menon AA, Berg DD, Brea EJ, Deutsch AJ, Kidia KK, Thurber EG, et al. A case of COVID-19 and Pneumocystis jirovecii coinfection. Am J Respir Crit Care Med. 2020;202(1):136-8. https://doi.org/10.1164/rccm.2020030766LE.

10. Bhat P, Noval M, Doub JB, Heil E. Concurrent COVID-19 and Pneumocystis jirovecii pneumonia in a severely immunocompromised 25-year-old patient. Int J Infect Dis. 2020;5(99):119-21. https://doi.org/10.1016/j.ijid.2020.07. 061.

11. Pasqualotto AC, Quieroz-Telles F. Histoplasmosis dethrones tuberculosis in Latin America. Lancet Infect Dis. 2018;18(10):1058-60. https://doi.org/10.1016/S14733099(18)30373-6.

12. Falci DR, Monteiro AA, Braz Caurio CF, Magalhães TCO, Xavier MO, Basso RP, et al. Histoplasmosis, an underdiagnosed disease affecting people living with HIV/AIDS in Brazil: results of a multicenter prospective cohort study using both classical mycology tests and Histoplasma urine antigen detection. Open Forum Infect Dis. 2019. https://doi. org/10.1093/ofid/ofz073.

13. Pan American Health Organization (PAHO), World Health Organization (WHO) (2020) Guidelines for diagnosing and managing disseminated histoplasmosis among people living with HIV.

14. Cáceres DH, Samayoa BE, Medina NG, Tobón AM, Guzmán BJ, Mercado D, et al. Multicenter validation of commercial antigenuria reagents to diagnose progressive disseminated histoplasmosis in people living with HIV/ AIDS in two Latin American countries. J Clin Microbiol. 2018;56(6):e01959-e2017. https://doi.org/10.1128/JCM. 01959-17.

15. Bongomin F, Govender NP, Chakrabarti A, Robert-Gangneux F, Boulware DR, Zafar A, et al. Essential in vitro diagnostics for advanced HIV and serious fungal diseases: international experts' consensus recommendations. Eur J Clin Microbiol Infect Dis. 2019;38(9):1581-4. https://doi. org/10.1007/s10096-019-03600-4.

16. BRASIL, Ministério da Saúde M. Boletim epidemiológico. Brasilia, v. 49, n. 53. In: www.aids.gov.br. Published 2018.

Publisher's Note Springer Nature remains neutral with regard to jurisdictional claims in published maps and institutional affiliations. 